\title{
Gestão de Pessoas no Terceiro Setor: motivações dos voluntários da Fundação Cidade Viva
}

\section{Third Sector HRM: Volunteers motivations at Cidade Viva Foundation}

\author{
ISMENIA GUEDES DUARTE \\ Universidade Federal da Paraíba \\ ismeniaguedes@yahoo.com.br \\ CARLOS EDUARDO CAVALCANTE \\ Universidade Federal da Paraíba \\ cavalcanteeduardo@gmail.com \\ RICARDO RIBEIRO ROCHA MARQUES \\ Universidade Federal da Paraíba \\ admricardorrmarques@gmail.com
}

\section{RESUMO}

O Terceiro Setor nos últimos anos revelou-se uma temática de estudo muito rica em descobertas e contribuições para a sociedade. Composto essencialmente por trabalhadores voluntários, esse campo vai de encontro a muitas premissas estabelecidas pelo pensamento capitalista e instrumental vigente na grande maioria dos países. Levando em consideração suas particularidades, este estudo visa a identificar os motivos pelos quais pessoas permanecem no trabalho voluntário na Cidade Fundação Viva, em João Pessoa (PB). A amostra é composta de voluntários que atuam há pelo menos um ano e alcançou 122 questionários, por acessibilidade, em um universo aproximado de 350 voluntários. O modelo teórico utilizado, proposto por Cavalcante (2012), explica as motivações de manter-se na tarefa voluntária em cinco perfis, variando de altruísmo a egoísmo. Os dados foram tratados por 
média, desvio-padrão e coeficiente de variação. Com base nos resultados, os motivos altruístas e de aprendizado apresentaram maiores médias, o que mostra que as razões para continuar a trabalhar como voluntários na Cidade Fundação Viva estão relacionadas com a busca de conhecimento e autossacrifício.

Palavras-chave: Trabalho voluntário; motivação do trabalhador voluntário; razões para permanecer.

\section{Abstract}

The Third Sector in recent years has proved to be a very rich study theme in discoveries and contributions to society. Essentially composed of volunteers, this field goes against many assumptions established by the existing capitalist and instrumental thinking in most countries. Taking into consideration its peculiarities this study aims to identify the reasons why people remain in volunteer work in the City Viva Foundation in João Pessoa (PB). The sample is composed of volunteers working for at least one year and reached 122 questionnaires, accessibility in an approximate population of 350 volunteers. The theoretical model used, proposed by Cavalcante (2012), explains the motivation to keep up the voluntary task in five profiles, ranging from selflessness to selfishness. The data were analyzed by mean, standard deviation and coefficient of variation. Based on the results, the altruistic motives and learning had higher averages, which shows that the reasons for continuing to work as volunteers in the City Viva Foundation are related to the search for knowledge and self-sacrifice.

Keywords: Volunteering; volunteer motivation; reasons to stay.

\section{INTRODUÇÃo}

O papel do Terceiro Setor na sociedade atual é um tema que requer atenção significativa. Conhecer o impacto da atuação desse setor na sociedade e suas formas de organização se tornou uma necessidade permanente, em virtude do aumento considerável de entidades privadas sem fins lucrativos que proporcionam serviços públicos às coletividades nas últimas décadas. Diante da incapacidade do Estado em atender às demandas da sociedade nas mais diversas áreas, como saúde, educação, lazer, meio ambiente e outras, emanou-se dos movimentos sociais oriundos da sociedade civil uma forma de organização específica: a de fins públicos, sem ser ligada ao Estado. 
O conjunto dessas instituições formam o Terceiro Setor. Uma organização desse setor pode ser definida como uma entidade legalmente constituída, não pertencente ao aparelho estatal, sem fins lucrativos, apta a gerir suas atividades e alicerçada no trabalho voluntário (SALAMON; ANHEIER, 1995).

Segundo Daudén (2013), o Brasil possui cerca de 290,7 mil fundações privadas e associações sem fins lucrativos, o que representa $5,2 \%$ de todas a entidades públicas e privadas cadastradas no Instituto Brasileiro de Geografia e Estatística (IBGE). Nesse contexto, o trabalho voluntário é alicerce importante, e a dificuldade em manter os colaboradores nessa atividade constitui um obstáculo à existência desse segmento. Alguns estudos confirmam esse fato, como as pesquisas realizadas por Townsend e Ebden (2008) sobre voluntariado ambiental na Grã-Bretanha, por Garner e Garner (2010) em organizações sem fins lucrativos na Califórnia do Sul nos Estados Unidos, e por Silva (2004) na cidade de Porto Alegre, Brasil. Segundo Daudén (2013), ocupamos a nona posição mundial em número bruto de voluntários, com cerca de 18 milhões de pessoas envolvidas nesse tipo de atividade. Assim a quantidade de envolvidos reforça a relevância empírica deste estudo.

A Fundação Cidade Viva está nesse universo. Instituição sem fins lucrativos, tem como objetivo geral a promoção da dignidade do ser humano por meio de ações voltadas ao desenvolvimento integral de suas potencialidades. Com suas atividades, a fundação vem contribuindo em áreas sociais relevantes como educação, esporte e cultura e saúde e na promoção da ética, direito, cidadania. As ações sociais realizadas são mantidas principalmente por voluntários que atualmente somam aproximadamente 350 pessoas em atividade contínua. A distinção entre contínuo e eventual deve ser considerada, pois o voluntário eventual tem menor envolvimento e sua rotatividade é programada, ao contrário do voluntário contínuo. Assim, entende-se que essa instituição é espaço privilegiado para a execução de um estudo sobre o voluntariado, pela sua variedade de atividades e pela quantidade de voluntários permanentes.

Essas características despertaram o interesse destes pesquisadores pela compreensão das razões que conduzem as pessoas a permanecerem envolvidas nessas iniciativas. Em complemento, o 
interesse da organização em conhecer os motivos que fazem com que seu grupo de voluntários permaneça atuando na ação voluntária, com a finalidade de reduzir a rotatividade desses indivíduos, é elemento que tornou o estudo viável.

Desse modo, o objetivo deste trabalho é identificar que razões levam os indivíduos a permanecerem atuando no trabalho voluntário na Fundação Cidade Viva. Em segundo plano, também se espera identificar potenciais motivos para que eles deixem a atividade e testar escala recentemente validada por Cavalcanti (2012). Deve ser destacado que este artigo é a continuação de um manuscrito que apresentou a primeira tentativa de validação da escala usada aqui como modelo teórico para a coleta e análise dos dados. Depois dele a escala já foi validada (CAVALCANTI, 2012), trabalhos já foram publicados em um evento (CAVALCANTI; SOUZA; MOL, 2014) e outros estão em avaliação em outros periódicos. Portanto, este trabalho tem a importância reforçada por ser um teste da escala em outro contexto e ser parte de uma linha de pesquisa que busca conhecer as motivações dos voluntários, por ora, do nordeste brasileiro. Esse fato demonstra, portanto, a relevância teórica do trabalho.

Para alcançar este objetivo o texto está assim estruturado: apresentam-se considerações sobre o Terceiro Setor e aspectos inerentes ao trabalho voluntário, seguidos da discussão de modelos de análise da motivação voluntária. Os atributos metodológicos aplicados à pesquisa, as discussões relativas aos dados coletados e aos resultados oriundos do estudo são conteúdo do tópico posterior. Por fim, são apresentadas as conclusões acerca das análises desenvolvidas e as referências que subsidiaram o arcabouço teórico e metodológico da pesquisa.

\section{TRABAlHo voluntáRIO: CONCEITOS E CARACTERÍSTICAS}

Um entendimento maior sobre o fenômeno do trabalho voluntário é fundamental, visto que se trata de uma característica indispensável ao funcionamento de instituições de Terceiro Setor. O trabalho voluntário pode ser definido como “a realização de qualquer atividade na qual a pessoa (voluntário) oferte, livremente, o seu tempo para beneficiar outras pessoas, grupos ou organizações, 
sem retribuição financeira ou material" (SOUZA; LAUTERT; HILLESHEIN, 2010).

No Brasil, a atividade voluntária é regulamentada pela Lei Federal n. 9.608, de 18 de fevereiro de 1998, que no art. 1o define voluntariado como "a atividade não remunerada, prestada por pessoa física a entidade pública de qualquer natureza, ou a instituição privada de fins não lucrativos, que tenha objetivos cívicos, culturais, educacionais, científicos, recreativos ou de assistência social, inclusive mutualidade" (BRASIL, 1998).

A Organização das Nações Unidas (ONU) (2003) assinala três critérios que devem nortear o trabalho voluntário e duas características necessárias ao mesmo. Os critérios são os seguintes: não deve ser praticado com vistas à obtenção de vantagem financeira; deve ser deliberado, realizado por vontade própria, livre de pressões externas; e traz benefícios tanto para quem recebe a ajuda quanto para aquele que executa a atividade. As duas características que, para a ONU, auxiliam na definição de voluntariado dizem que ele pode ser realizado fora de organizações e que também pode ser feito de forma esporádica, sem a obrigatoriedade de um envolvimento regular nem de longo prazo.

Por fim, CAVALCANTI (2012) pontua as seguintes características do trabalho voluntário: pode ter ganhos financeiros, limitados ao custo de executar a atividade; é de decisão individual; permite receber benefícios, mentais ou físicos; é de natureza eventual ou permanente; e pode ou não ser executado sob as orientações de uma organização.

\subsection{Motivação no trabalho voluntário: modelo teórico da pesquisa}

As teorias sobre motivação no âmbito da Administração são muitas, mas, como indica Cavalcante (2012, p. 46), "as teorias usadas para entender a motivação no contexto voluntário são outras, e seu uso se justifica pela diferença que o trabalhador voluntário tem do trabalhador formal". O autor explica que, dentre as várias diferenças existentes entre o trabalhador voluntário e o trabalhador formal, a principal é justamente a motivação.

Com o objetivo de mensurar a motivação dos indivíduos para o trabalho voluntário, Cavalcante (2012) desenvolveu três modelos 
teóricos que relacionam cinco fatores de motivação - que oscilam entre altruísta e egoísta - avaliados em três momentos distintos: expectativas, razões para entrada e razões para permanência do indivíduo no trabalho voluntário. Lembre-se de que o atual estudo se limita a descrever as razões para permanência dos voluntários. Os fatores elencados foram: altruísta (relacionado ao autossacrifício); justiça social (com indicadores de igualdade); afiliação (reflete a busca de inserção em grupos); aprendizado (caracterizado pelo autodesenvolvimento); e egoísta (centrado no eu).

No mesmo estudo Cavalcante (2012) sugere um quarto modelo - os motivos de saída - que foi gerado com três fatores: “escassez de recursos" (aferem a saída do voluntariado pela falta de recursos); "motivos religiosos" (afetados pela percepção de religiosidade dos voluntários); e "motivos pessoais" (estimam a saída por motivos de cunho pessoal). Cada variável se relaciona com indicadores referentes a algumas possíveis condições de realidade percebidas pelos indivíduos que os levariam a desligar-se do trabalho voluntário. Esse modelo será usado para atingir o segundo objetivo deste estudo, isto é, identificar potenciais motivos para a saída da atividade.

No referido estudo, os significados das variáveis referentes a expectativas, motivos de entrada e de permanência se pautaram na Teoria da Expectância de Vroom (1964). Para esse autor, “o processo de motivação deve ser explicado em função dos objetivos e das escolhas de cada pessoa e das suas expectativas em alcançar tais objetivos" (VROOM, 1964).

\section{Metodologia}

Esta investigação ocorreu com os voluntários envolvidos na execução das atividades contínuas dos eixos de atuação da Fundação Cidade Viva. Devido ao seu interesse empírico, a pesquisa apresenta natureza aplicada e nela utilizou-se uma abordagem quantitativa em razão de o instrumento utilizado apresentar variáveis que se associam. Do ponto de vista dos seus objetivos, a pesquisa foi definida como descritiva, e quanto aos procedimentos técnicos utilizados este trabalho se caracterizou como sendo uma pesquisa de campo.

O universo deste estudo é formado pelos indivíduos que compõem o conjunto de voluntários que atuam nas ações da Fundação 
Cidade Viva (aproximadamente 350 indivíduos). Já a amostra foi composta por 122 voluntários que participam há pelo menos um ano da fundação. Essa escolha se justificou pela pretensão deste trabalho em investigar os motivos de permanência do indivíduo voluntário, e, para isso, foram considerados elementos da amostra apenas os sujeitos que atuam no voluntariado de forma mais prolongada, diferenciando-os dos que fazem parte das atividades eventualmente ou com menos de um ano.

O instrumento utilizado nesta pesquisa foi o questionário elaborado por Cavalcante (2012) para mensurar as motivações de permanência na ação voluntária e se divide em três partes. Na primeira, perguntou-se "por que eu permaneço na Cidade Viva?" e foram apresentados em forma de questões os 22 indicadores dos cinco perfis de motivação definidos pelo autor do instrumento.

A segunda parte do questionário perguntou "por que eu sairia da Cidade Viva?" e abrangeu os motivos contidos nos indicadores relacionados com as variáveis "escassez de recursos", "motivos religiosos" e "motivos pessoais", elencando oito descrições para cada uma. Por fim, a terceira parte apresentou 12 perguntas com o objetivo de traçar o perfil sociodemográfico dos voluntários, bem como investigar os possíveis vínculos existentes entre eles e a atividade voluntária.

A cada indicador de permanência e saída foi atribuída uma escala de 1 a 10, pela qual o pesquisado pôde especificar seu nível de concordância com cada afirmação contida nas questões. As respostas foram graduadas de "discordo totalmente" (número 1) a "concordo totalmente" (número 10).

Os voluntários da Fundação Cidade Viva são agrupados em equipes denominadas de ministérios, e cada um desenvolve uma atividade diferente pertencente a algum dos eixos de ação da entidade. $O$ instrumento de coleta de dados foi aplicado nas reuniões dessas equipes que aconteceram na sede da Fundação, localizada na cidade de João Pessoa (PB), entre os meses de fevereiro e maio de 2013. A análise desses dados baseou-se nas medidas estatísticas média, moda, desvio-padrão e coeficiente de variação. 


\section{ANÁlise dos dADOS}

Para a apresentação e discussão dos resultados, definiram-se três linhas: (1) perfil sociodemográfico dos sujeitos da pesquisa e seus possíveis vínculos com o voluntariado; (2) identificação dos motivos que mantêm os indivíduos na atividade voluntária; e (3) identificação dos motivos que os levam ao desligamento do trabalho voluntário.

Antes de se conhecerem os resultados obtidos, são apresentados dados acerca da escala em teste, por meio de consistência interna e análise fatorial da escala. A primeira parte do instrumento, que mede as motivações para permanência, obteve um alpha de 0.88 , e a segunda parte, com os potenciais motivos para saída dos voluntários, alcançou um alpha de 0.62. Esses valores permitem assumir que a primeira parte do instrumento apresentou uma consistência interna muito boa e a segunda parte, uma consistência aceitável, garantindo, em boa gradação, que o instrumento é confiável.

Quanto aos resultados da análise fatorial, pode-se dizer que bons resultados foram encontrados: o KMO apresentou um valor de 0,77; as Matrizes Anti-imagem indicaram o poder de explicação dos fatores em cada variável utilizada, com um valor na casa de 0,6 e todos os demais acima de 0,710 , alcançando bons valores; e foi confirmada a existência de cinco fatores (altruísta; de justiça social; de afiliação; de aprendizado; e egoísta) para o entendimento da motivação voluntária em contexto nacional e explicação de $64 \%$ da variação. Assim, seguem-se as análises.

\subsection{Dados sociodemográficos e vínculos com o voluntariado}

Pode ser definido que o perfil-padrão da amostra pesquisada é de uma mulher, em torno de 30 anos, casada, com pós-graduação, de classe média-alta e empregada. Conclui-se também que seus familiares e círculo social também fazem/fizeram atividades voluntárias. Esses resultados estão em linha com outros realizados em contexto semelhante.

Paul (1999), em pesquisa realizada via internet com cidadãos americanos de diversas organizações voluntárias, concluiu que $77 \%$ eram mulheres, cerca da metade era pelo menos graduada e de classe média e que $75 \%$ haviam feito trabalhos voluntários no 
último ano. Destaca-se esse estudo porque, mesmo tendo como característica a coleta indiscriminada de dados de voluntários, revelou resultados semelhantes.

No Brasil os resultados também estão próximos dos obtidos nesta pesquisa. Em 2011 o IBGE e a Rede Brasil Voluntário realizaram um levantamento em oito cidades do país e concluíram que a maioria eram mulheres, casadas, empregadas, com média de 39 anos, de classes média baixa/alta e com pelo menos nível superior incompleto.

No México, Butcher (2010) discutiu os resultados da Pesquisa Nacional de Solidariedade e de Voluntariado (ENSAV), um estudo de dois anos realizado naquele país. As motivações pelas quais os indivíduos agem em favor dos outros refletem fortemente os valores da família - que tem um histórico no voluntariado - e a vontade de cuidar dos outros. Butcher (2010) também verificou que mais da metade dos voluntários tem familiares que participam dessas atividades. Ainda ficou claro que 57\% dos respondentes tiveram influência da família para se juntar à atividade e $23 \%$ foram influenciados pelo cônjuge ou por amigos.

Então, essa aproximação com amostras de pesquisas realizadas em contextos semelhantes permite entender que os resultados alcançados aqui têm um bom poder de generalização.

\subsection{Motivos de permanência no trabalho voluntário da Fun- dação Cidade Viva}

Os motivos de permanência envolvem indicadores referentes às razões que estimulam os voluntários da Fundação Cidade Viva a se manterem na atividade voluntária. O Quadro 1 expõe as médias, desvios-padrão e coeficientes de variação de cada indicador (questão) contido no instrumento de coleta de dados. 
Quadro 1: Dados quantitativos dos perfis relacionados à permanência dos voluntários

\begin{tabular}{|c|c|c|c|c|c|c|c|}
\hline Perfil & Questão & $\begin{array}{c}\text { Média } \\
\text { questão }\end{array}$ & $\begin{array}{c}\text { Desv Pad } \\
\text { questão }\end{array}$ & $\begin{array}{c}\text { Coef de } \\
\text { Var } \\
\text { questão }\end{array}$ & $\begin{array}{c}\text { Média } \\
\text { perfil }\end{array}$ & $\begin{array}{c}\text { DesvPad } \\
\text { perfil }\end{array}$ & $\begin{array}{c}\text { Coef Var } \\
\text { perfil }\end{array}$ \\
\hline \multirow{5}{*}{ Altruísta } & 1 & 8,81 & 1,4 & $15,94 \%$ & \multirow{5}{*}{8,61} & \multirow{5}{*}{1,55} & \multirow{5}{*}{$18,02 \%$} \\
\hline & 2 & 8,09 & 1,58 & $19,47 \%$ & & & \\
\hline & 3 & 8,79 & 1,39 & $15,84 \%$ & & & \\
\hline & 4 & 8,32 & 1,76 & $21,15 \%$ & & & \\
\hline & 5 & 9,03 & 1,41 & $15,65 \%$ & & & \\
\hline \multirow{4}{*}{ Justiça Social } & 6 & 8,46 & 1,66 & $19,68 \%$ & \multirow{4}{*}{7,66} & \multirow{4}{*}{2,29} & \multirow{4}{*}{$29,96 \%$} \\
\hline & 7 & 7,2 & 2,43 & $33,70 \%$ & & & \\
\hline & 8 & 7,43 & 2,34 & $31,45 \%$ & & & \\
\hline & 9 & 7,54 & 2,48 & $32,90 \%$ & & & \\
\hline \multirow{4}{*}{ Afiliação } & 10 & 8,2 & 2,18 & $26,56 \%$ & \multirow{4}{*}{7,27} & \multirow{4}{*}{2,7} & \multirow{4}{*}{$37,15 \%$} \\
\hline & 11 & 8,19 & 2,25 & $27,47 \%$ & & & \\
\hline & 12 & 6,39 & 2,99 & $46,80 \%$ & & & \\
\hline & 13 & 6,39 & 2,68 & $41,87 \%$ & & & \\
\hline \multirow{4}{*}{ Aprendizado } & 14 & 7,62 & 2,59 & $33,94 \%$ & \multirow{4}{*}{8,66} & \multirow{4}{*}{1,86} & \multirow{4}{*}{$21,47 \%$} \\
\hline & 15 & 8,88 & 1,52 & $17,10 \%$ & & & \\
\hline & 16 & 9,12 & 1,1 & $12,11 \%$ & & & \\
\hline & 17 & 9,07 & 1,38 & $15,21 \%$ & & & \\
\hline \multirow{5}{*}{ Egoísta } & 18 & 3,94 & 3,08 & $78,12 \%$ & \multirow{5}{*}{4,99} & \multirow{5}{*}{3,52} & \multirow{5}{*}{$70,51 \%$} \\
\hline & 19 & 2,39 & 2,5 & $104,61 \%$ & & & \\
\hline & 20 & 7,36 & 2,66 & $36,15 \%$ & & & \\
\hline & 21 & 5,01 & 3,42 & $68,31 \%$ & & & \\
\hline & 22 & 6,25 & 3,56 & $57,01 \%$ & & & \\
\hline
\end{tabular}

Fonte: Dados da pesquisa (2013).

De acordo com o Quadro 1, percebe-se que o perfil "altruísta" apresentou a segunda maior média nas respostas dos voluntários da Fundação Cidade Viva, que corresponde a 8,61. Além disso, trouxe um desvio-padrão de 1,55, o menor entre os cinco fatores, e um coeficiente de variação de apenas 18,02\%, o que aponta respostas homogêneas com relação à média, sem oscilações que devam ser levadas em consideração. Isso significa que os voluntários que atuam nas mais diversas áreas de ação social da Fundação consideram que a doação de si mesmos sem esperar retornos pessoais é uma razão que influencia notadamente a permanência no voluntariado da instituição. 
A questão 5, que obteve média 9,03 - a maior dentro do perfil altruísta -, diz respeito ao indicador "porque considero meu trabalho importante", o que manifesta a percepção de relevância do trabalho voluntário quando os sujeitos avaliam a permanência na Fundação. Esse trabalho se materializa no auxílio psicológico, material e espiritual aos que se encontram em hospitais, presídios, asilos, abrigos para menores em situação de risco, moradores de rua, bem como a inclusão de pessoas surdas e atividades relacionadas com os ministérios que servem às igrejas às quais a Fundação Cidade Viva pertence como música, teatro, integração entre os membros e ensino de valores cristãos.

Já a questão que apresentou menor média $(8,09)$ foi a que representa o indicador 2 ("porque tenho conseguido mudar a vida das pessoas"), com desvio-padrão de 1,58. Contudo, percebe-se que a distância entre a média mais alta e a mais baixa entre os indicadores do perfil é pequena, e ambas apresentam desvio-padrão e coeficientes de variação baixos, o que demonstra que não existem oscilações consideráveis entre as respostas. Isso indica que a consciência que os sujeitos têm da melhoria trazida por seu trabalho à vida das pessoas também é uma razão importante para continuar o serviço voluntário.

Percebe-se que o perfil altruísta demonstra um alinhamento com os valores cristãos que norteiam a missão da Fundação Cidade Viva, como o amor ao próximo expresso por meio do serviço, sem buscar retribuições. Isso se evidencia pelo fato de o perfil trazer a segunda maior média $(8,61)$ entre os cinco fatores de motivação, muito próxima da maior média entre os perfis, que foi de 8,65. Para a organização, é importante que os motivos dos participantes estejam em sintonia com os dela, pois a identificação dos voluntários com os princípios que orientam a Fundação Cidade Viva servirá de estímulo à permanência no voluntariado.

No que diz respeito ao perfil "justiça social", conforme apresentado no Quadro 1, esse fator traz a terceira maior média entre os perfis, correspondendo a 7,66, desvio-padrão de 2,29 e coeficiente de variação de 29,96\% (o terceiro maior com relação aos demais). Tal coeficiente permite perceber uma variação maior com relação às respostas desse fator se comparado ao perfil "altruísta", por exem- 
plo. Constatou-se uma moderada dispersão dos valores, ou seja, as informações fornecidas pelos voluntários se apresentaram de forma mais heterogênea; contudo, os resultados ainda possibilitam afirmar que há uma coesão razoável entre os sujeitos da amostra no que diz respeito a concordarem que motivos relacionados ao perfil "justiça social" são relevantes para a permanência no voluntariado.

Como é possível notar, dentro do perfil "justiça social" o indicador 6 ("porque estou ajudando as comunidades") obteve a maior média $(8,46)$ e o menor desvio-padrão $(1,66)$, com coeficiente de variação abaixo de $20 \%$. Isso mostra que os voluntários consideram que o auxílio oferecido às comunidades onde a Fundação Cidade Viva atua tem influência significativa para o prosseguimento na ação voluntária.

Já o indicador 7 ("porque estou corrigindo injustiças sociais nas comunidades") teve a menor média do fator $(7,2)$ e o maior desvio-padrão $(2,43)$, apontando que as respostas relacionadas a essa questão foram mais heterogêneas que as outras dentro desse perfil. Aqui se percebe que não há um consenso dos voluntários da amostra no que tange ao seu papel como sujeito ativo no processo de correção de injustiças na sociedade.

No que concerne ao fator "afiliação", a média obtida foi 7,27 - a segunda menor entre os fatores -, desvio-padrão de 2,7 e coeficiente de variação de 37,15\%. Quando se associa esse desvio-padrão à média apresentada, apreende-se que há uma variação maior nas respostas, principalmente naquelas referentes aos indicadores 12 ("porque estou fazendo novos amigos") e 13 ("porque estou convivendo com outras pessoas"), que apontaram médias mais baixas (ambos com 6,39) e os desvios-padrão mais altos do perfil - 2,99 e 2,68, respectivamente.

Nota-se certa homogeneidade com relação às questões 10 ("porque estou com pessoas com os mesmos interesses") e 11 ("porque sinto que estou fazendo parte de um grupo"), que trouxeram médias praticamente iguais (8,20 e 8,19, respectivamente) e desvios-padrão menores com relação às médias (2,18 e 2,25, respectivamente).

Pode-se concluir que os indicadores 12 e 13, que tratam de fazer novas amizades e conviver com outras pessoas, foram os elementos que contribuíram para maior oscilação das respostas do perfil "afiliação", não sendo considerados tão importantes para a permanência 
no trabalho voluntário da Fundação Cidade Viva. Por outro lado, os motivos que versam sobre fazer parte de um grupo com mesmos interesses e a respeito do sentimento de afiliação a esse grupo são avaliados como relevantes para a continuidade no voluntariado.

Os voluntários da Fundação Cidade Viva são reunidos em grupos distintos - denominados de ministérios - de acordo com a identificação com os objetivos de cada grupo. Caso uma pessoa seja um profissional da área de saúde, por exemplo, ele poderá atuar junto a outros profissionais do mesmo ramo na assistência à saúde de pessoas menos favorecidas. Isso pode fazer com que ele se sinta mais harmonizado com o grupo, o que o levará a ter um interesse maior em permanecer na ação voluntária. Interesses em comum foram apontados pelos pesquisados como sendo a razão mais importante desse perfil para continuar atuando na ação voluntária (indicador 10), apesar de os motivos do fator como um todo terem ficado em segundo plano na percepção dos voluntários.

O perfil que obteve maior média, quando consideradas todas as suas variáveis, foi o "aprendizado". Percebe-se que os indicadores 15 ("porque estou aprendendo novos conhecimentos"), 16 ("porque estou tendo novos desafios e experiências") e 17 ("porque estou aprendendo algo") alcançaram médias muito aproximadas, desvios-padrão relativamente pequenos e coeficientes de variação baixos, sendo os três considerados motivos significativos para permanecer no voluntariado da Fundação Cidade Viva. Os coeficientes de variação de 17,10\%, 12,11\% e 15,21\% apontados no Quadro 2 demonstram que há entre os voluntários certo consenso quanto à importância dos motivos apresentados nos indicadores mencionados.

A média mais baixa entre os indicadores pertence à questão 14 ("porque estou aprendendo a lidar com pessoas"), que corresponde a 7,62, com desvio-padrão mais alto do fator "aprendizado" $(2,59)$. Observando o coeficiente de variação desse indicador (33,94\%), nota-se que nas respostas referentes a essa questão houve uma divergência maior do que nas demais questões do perfil; contudo, ainda assim há que se considerar a relevância desse motivo por parte da maioria dos pesquisados.

Destaca-se aqui que mais de $70 \%$ dos envolvidos nas atividades da Fundação possuem formação acadêmica concluída, e desse 
percentual a maioria apresenta pós-graduação. Isso pode ser particularmente interessante para a organização quando os voluntários se mostram motivados a continuar na atividade para dividir seus conhecimentos com pessoas assistidas pelas ações promovidas e até mesmo com outros voluntários, ou ainda utilizar essas capacidades para melhorar os vários processos existentes dentro da instituição.

Por fim, no que tange ao perfil "egoísta", foi a menor média entre os cinco fatores de motivação para permanência no serviço voluntário, com 4,99, e apresentou um desvio-padrão expressivo de 3,52, com um elevado coeficiente de variação de 70,51\%. Isso revela que as respostas fornecidas pelos pesquisados são bastante heterogêneas e mostram grandes oscilações. Conclui-se que, na percepção dos voluntários da Fundação Cidade Viva, os motivos apresentados por esse perfil, em sua maioria, são menos importantes para a permanência no voluntariado.

O indicador 19 ("porque estou preenchendo tempo livre") obteve a menor média $(2,39)$, o que mostra que a maioria dos voluntários considera que a falta de tempo livre não é impedimento para se manter na atividade.

Já o indicador 20 ("porque estou me sentindo melhor como pessoa") apresenta a maior média do fator $(7,36)$. E ainda que o desvio-padrão $(2,66)$ tenha alguma significância, não descaracteriza completamente a relevância desse motivo, o que permite inferir que o sentimento de bem-estar produzido pelo trabalho voluntário leva a pessoa a continuar as atividades.

A Figura 1 expõe a relação entre as médias e desvios-padrão de cada fator de motivação para permanência no trabalho voluntário analisado.

É possível concluir que os sujeitos que permanecem atuando no voluntariado da Fundação Cidade Viva não esperam que a atividade os compense com reconhecimento pessoal, satisfação ou uma melhoria na autoestima; entretanto, valorizam a sensação de contentamento gerada pelo trabalho voluntário, por meio de valores altruístas e de aprendizado.

Esses resultados estão em sintonia com os encontrados em Clary, Snyder e Ridge (1992). Eles também concluíram em suas pesquisas que características motivacionais influenciadas pelo altruísmo 
Figura 1: Fatores de motivação para permanência no voluntariado

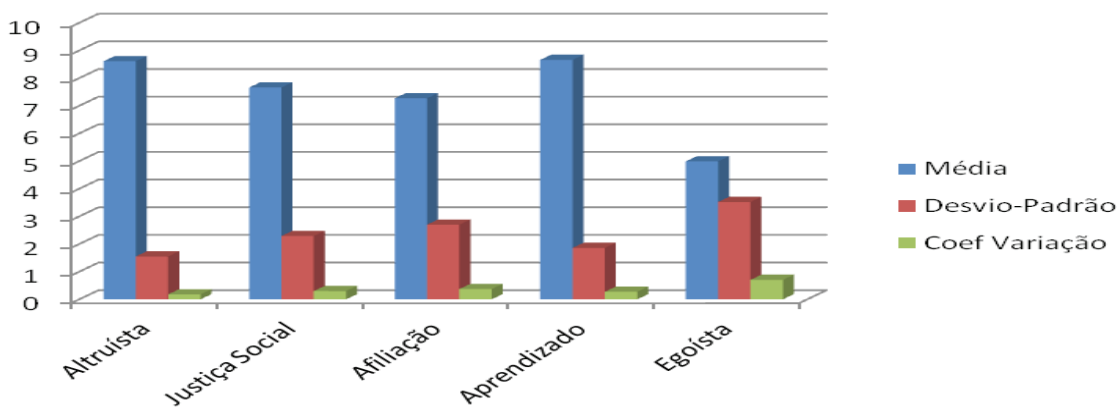

Fonte: Dados da pesquisa (2013).

estimulariam o indivíduo a se tornar voluntário. Para eles, os sujeitos se voluntariam com a finalidade de satisfazer necessidades/motivos pessoais e se mantêm na atividade caso essas necessidades/motivos sejam alcançadas (CLARY, SNYDER; RIDGE, 1992).

Também pode ser observada a busca pelo autodesenvolvimento, resultados semelhantes aos observados por Hakinson e Rochester (2005) que concluíram, entre seus pesquisados, que há a possibilidade de adquirir novos conhecimentos, tanto os vinculados à carreira ou não quando executam atividades voluntárias. Perold e Tapia (2007) também chegaram às mesmas conclusões em pesquisa realizada no Chile: voluntários relataram que o programa do qual fazem parte é muito apreciado por oferecer a oportunidade de exercer as suas competências e por isso ser valorizados. Já Dolnicar e Randle (2007), em pesquisa realizada na Austrália com cerca de 12 mil indivíduos, encontraram motivações como "ganhar experiência", "melhorar habilidades" e "usar habilidades" entre seus interesses.

\subsection{Motivos de saída do trabalho voluntário da Fundação Cidade Viva}

Os motivos de saída reúnem os indicadores que apontam razões para deixar a atividade voluntária da Fundação Cidade Viva. Esses indicadores estão divididos em três variáveis: "escassez de recursos", "motivos religiosos" e "motivos pessoais". As médias, desvios-padrão e coeficientes de variação de cada indicador (ques- 
tão) presente no instrumento de pesquisa, assim como de cada variável que os agrupa, estão apresentados no Quadro 2.

Quadro 2: Dados quantitativos das variáveis relacionadas à saída dos voluntários

\begin{tabular}{|c|c|c|c|c|c|c|c|}
\hline Variável & Questão & $\begin{array}{c}\text { Média da } \\
\text { questão }\end{array}$ & $\begin{array}{c}\text { Desvio } \\
\text { padrão da } \\
\text { questão }\end{array}$ & $\begin{array}{l}\text { Coeficiente } \\
\text { de variação } \\
\text { da questão }\end{array}$ & $\begin{array}{c}\text { Média do } \\
\text { perfil }\end{array}$ & $\begin{array}{c}\text { Desvio } \\
\text { padrão do } \\
\text { perfil }\end{array}$ & $\begin{array}{c}\text { Coeficiente } \\
\text { de variação } \\
\text { do perfil }\end{array}$ \\
\hline \multirow{3}{*}{ Escassez de recursos } & 1 & 1,07 & 0,3 & $27,61 \%$ & \multirow{3}{*}{1,09} & \multirow{3}{*}{0,4} & \multirow{3}{*}{$36,62 \%$} \\
\hline & 2 & 1,16 & 0,59 & $51,07 \%$ & & & \\
\hline & 3 & 1,06 & 0,23 & $21,72 \%$ & & & \\
\hline \multirow{2}{*}{ Motivos religiosos } & 4 & 4,64 & 3,81 & $82,12 \%$ & \multirow{2}{*}{4,58} & \multirow{2}{*}{3,8} & \multirow{2}{*}{$82,94 \%$} \\
\hline & 5 & 4,53 & 3,81 & $84,12 \%$ & & & \\
\hline \multirow{3}{*}{ Motivos pessoais } & 6 & 1,84 & 1,46 & $79,63 \%$ & \multirow{3}{*}{1,69} & \multirow{3}{*}{1,44} & \multirow{3}{*}{$85,19 \%$} \\
\hline & 7 & 1,02 & 0,14 & $13,79 \%$ & & & \\
\hline & 8 & 2,12 & 1,79 & $84,29 \%$ & & & \\
\hline
\end{tabular}

Fonte: Dados da pesquisa (2013).

Os indicadores da variável "escassez de recursos" apresentaram médias e desvios-padrão baixos e, consequentemente, uma média baixa para a variável como um todo. O coeficiente de variação de $36,62 \%$ permite perceber alguma oscilação nas respostas, mas não descaracteriza a pouca relevância atribuída a essa variável. Isto quer dizer que a falta de recursos - sejam materiais, sejam financeiros, sejam humanos - não é considerada uma motivação importante para deixar a atividade voluntária.

Com relação à variável "motivos religiosos", os indicadores apontaram as médias mais altas entre todas as questões relacionadas a motivos de saída e também maiores desvios-padrão e coeficientes de variação. Entretanto, as médias alcançadas (4,64 e 4,53) exprimem um meio-termo entre os extremos "discordo totalmente" e "concordo totalmente", o que, juntamente com as oscilações significativas nas respostas demonstradas pelos coeficientes apresentados, não permite uma análise precisa com relação à importância desses motivos para a decisão de desligamento, ainda que seja possível afirmar que estas foram as únicas motivações de saída que demonstraram alguma relevância entre os pesquisados. 
A última variável relacionada a motivações de saída é referente a "motivos pessoais", e seus indicadores obtiveram médias baixas $(1,84,1,02$ e 2,12), o que permite concluir que tais motivos também não influenciaram fortemente uma decisão de saída do voluntariado. Os desvios-padrão dos indicadores 6 e 8 (1,46 e 1,79), juntamente com seus altos percentuais dos coeficientes de variação $(79,63 \%$ e $84,29 \%$ ), mostram divergências nas respostas, mas isso não altera a caracterização dos motivos como pouco relevantes para o desligamento da atividade, em virtude das médias significativamente baixas.

A Figura 2 exibe a relação entre as médias e desvios-padrão das três variáveis que motivam a saída do trabalho voluntário.

Figura 2: Variáveis de saída do voluntariado

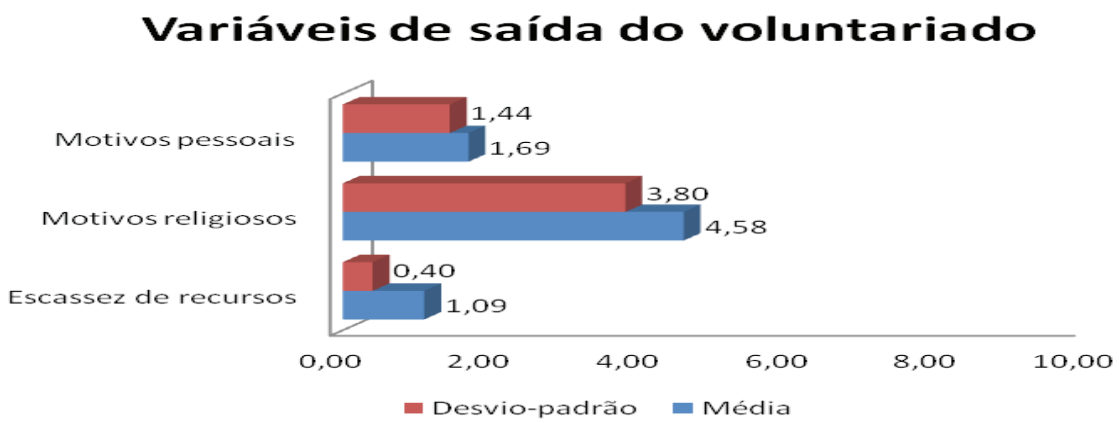

Fonte: Dados da pesquisa (2013).

Conforme explicitado na Figura 2 é possível afirmar que, para a amostra da pesquisa, nenhuma motivação pessoal ou ligada à falta de recursos se apresenta como suficientemente forte para provocar a saída do voluntariado. Quanto aos motivos religiosos, houve oscilações entre as respostas, em que um grupo de voluntários indicou que deixaria a atividade caso perdesse a fé em Deus ou o amor ao próximo, mas grande parte ainda considera que razões religiosas não afetariam sua permanência no serviço voluntário.

Foi disponibilizado um campo denominado "Outro", para preenchimento por escrito, caso algum voluntário quisesse elencar um motivo não relacionado entre os indicadores que o levariam a 
sair do serviço voluntário. Apenas cinco pesquisados optaram por utilizar o espaço e indicaram as seguintes razões: "eu sairia se fosse direcionado por Deus"; "eu sairia se os objetivos da Cidade Viva não fossem claros"; "eu sairia se a instituição perdesse sua característica de transparência e probidade"; "eu sairia temporariamente para realizar outras atividades"; e "eu sairia se não sentisse mais a vontade de Deus nessa comunidade".

Diante das respostas subjetivas dos voluntários, é possível entender que, além de motivos religiosos, outros relacionados com a idoneidade da Fundação Cidade Viva poderiam levar o sujeito ao desligamento da atividade voluntária.

Estes resultados estão em linha com os encontrados em Cavalcante (2012), que realizou pesquisa em instituição de cunho religioso e concluiu que motivações pessoais e religiosas também seriam potenciais razões para saída dos voluntários da atividade.

\section{CONSIDERAÇõES FINAIS}

A consolidação do Terceiro Setor no Brasil é um fenômeno que exige estudos que permitam melhor compreensão dele. O setor ainda é carente de fundamentos científicos que possam ajudar no desenvolvimento dos recursos humanos dentro de suas especificidades, tendo em vista que é essencialmente alicerçado no trabalho voluntário. Procurou-se conhecer os motivos que levam o indivíduo a permanecer atuando no voluntariado, o que é condição essencial para resolver problemas de rotatividade e planejamento com relação a pessoal e alcançar melhores resultados na ação voluntária.

Destaca-se que, para a maioria dos sujeitos, o casamento não impede a atuação no serviço voluntário, tampouco o fato de exercer alguma atividade laboral. Isso quer dizer que, por mais que o voluntário possua outras tarefas em seu cotidiano, a escassez de tempo não representa obstáculo se agir e que, consequentemente, preencher tempo livre não é elemento motivador para conservar-se no trabalho voluntário.

Ressalta-se que, embora os voluntários tenham revelado que os motivos encontrados nos perfis "aprendizado" e "altruísta" são mais significativos para manterem-se no trabalho voluntário, os 
demais perfis também apresentaram indicadores que explicitam outras razões consideradas relevantes pelos indivíduos da amostra.

A noção de ajudar as comunidades a melhorarem a qualidade de vida, inerente ao perfil "justiça Social", o fato de pertencer a um grupo que possui os mesmos interesses, que é motivo próprio do perfil "afiliação", e o sentimento de bem-estar produzido pela atividade voluntária, que caracteriza o perfil "egoísta", são estímulos para que os indivíduos se mantenham no voluntariado e também devem ser levados em consideração pela Fundação Cidade Viva.

Com relação aos motivos que levam os indivíduos ao desligamento do trabalho voluntário, observou-se que a variável "motivos religiosos", que abrange razões como a perda da fé em Deus e a falta de amor ao próximo, foi considerada mais significativa. A instituição pesquisada, embora sendo uma organização de Terceiro Setor, é manifestamente cristã e um dos seus objetivos diz respeito à promoção de valores religiosos cristãos. Esse caráter confessional dela ajuda a compreender a importância atribuída pelos pesquisados aos motivos religiosos para considerar a possibilidade de desligamento da atividade voluntária.

Em linhas gerais, de acordo com as informações obtidas e analisadas neste estudo, pode-se concluir que os motivos que levam os indivíduos a permanecer atuando no trabalho voluntário da Fundação Cidade Viva são predominantemente relacionados com o autodesenvolvimento e o altruísmo. Razões como aprender novos conhecimentos e vivenciar novos desafios e experiências caminham juntamente com o sentimento de ajudar pessoas a mudarem de vida e levar esperança aos menos favorecidos. Percebe-se assim que os motivos apresentados pelos sujeitos como sendo mais relevantes para manter-se na atividade tanto estão centrados em si mesmo, como no próximo.

Uma limitação deste estudo é a tentativa de apreensão de um fenômeno fortemente subjetivo por meio de um instrumento quantitativo. Entretanto, os resultados demonstraram que a escala utilizada pode trazer resultados que auxiliem a instituição pesquisada a melhor acompanhamento dos seus voluntários. E também o fato de ser o primeiro teste da escala validada por Cavalcante (2012) pode 
não permitir maior amplitude de entendimento do sentimento dos pesquisados. Sob esta limitação está a sugestão de estudos futuros. Quanto a novas pesquisas deve ser destacada a necessidade de ainda buscar um melhor refinamento da escala utilizada. Apesar de ter alcançado bons resultados em teste de análise fatorial realizado com esta amostra, conforme pode ser observado no início da análise dos dados, uma das variáveis que inicialmente se acreditava fazer parte do fator "egoísta" - "(Permaneço) Porque estou me sentindo melhor como pessoa" - agrupou-se com as que medem o fator "aprendizado". Apesar de entender que essas variáveis têm maior nível de valores egoístas, essa interpretação parece ser insuficiente. Então, por ora, não há explicações teóricas nem empíricas para justificar essa movimentação, daí a necessidade de estudos futuros para buscar um entendimento dessa ocorrência.

\section{AGRADECIMENTO}

Nós agradecemos ao Conselho Nacional de Desenvolvimento Cientifico e Tecnológico por financiar este artigo.

\section{REFERÊNCIAS}

BRASIL. Lei n. 9.608, de 18 de fevereiro de 1998. Diário Oficial da União, Poder Executivo, Brasília, DF, 18 fev. 1998. Disponível em: <http://www.planalto.gov.br/ccivil_03/leis/L9608. htm>. Acesso em: 7 jan. 2013.

BUTCHER, J. Mexican solidarity: findings from a national study. Voluntas: International Journal of Voluntary and Nonprofit Organizations, v. 21, n. 2, p. 137-161, 2010.

. Motivação no Trabalho Voluntário: expectativas e motivos na Pastoral da Criança. 202 f. Tese (Doutorado em Administração) - Programa de Pós-Graduação em Administração, Universidade Federal do Rio Grande do Norte, Natal, 2012. Disponível em: <https://docs. google.com/viewer?a=v\&pid=sites\&srcid=ZGVmYXVsdGRvbWFpbnxwcm9mY2FybG9zZWR 1YXJkb2NhdmFsY2FudGV8Z3g6NDQyMTIyMmMyM2NiYThmNA>. Acesso em: 7 dez. 2013.

BUTCHER, J.; SOUZA, W. J. de; MOL, A. L. R. O que eu espero do trabalho voluntário? Proposição de um modelo teórico. In: ENCONTRO NACIONAL DE PESQUISADORES EM GESTÃO SOCIAL, 8., 27-30 abr. 2014, Cachoeira/BA. Anais...

CLARY, E. G.; SNYDER, M.; RIDGE, R. Volunteers' motivations. Nonprofit Management and Leadership, v. 2, n. 4, Summer 1992.

CNAAN, R. A.; AMROFELL, L. M. Mapping volunteer activity. Nonprofit and Voluntary Sector Quarterly, v. 23, n. 4, p. 335-351, 1994. 
CNAAN, R. A.; HANDY, F.; WADSWORTH, M. Defining who is a volunteer: Conceptual and empirical considerations. Nonprofit and Voluntary Sector Quarterly, v. 25, n. 3, p. 364-383, 1996.

DAUDÉN, L. O voo solidário. Revista IstoÉ, 23 jan. 2013. Disponível em: <http://www.istoe. com.br/reportagens/269058_O+VOO+SOLIDARIO?pathImagens=\&path=\&actualArea=interna 1Page>. Acesso em: 20 jan. 2013.

DOLNICAR, S.; RANDLE, M. What motivates which volunteers? Psychographic heterogeneity among volunteers in Australia. Voluntas - International Journal of Voluntary and Nonprofit Organizations, v. 18, n. 2, p. 135-155, 2007.

GARNER, J. T.; GARNER, L. T. Volunteering an opinion: Organizational voice and volunteer retention in nonprofit organizations. Nonprofit and Voluntary Sector Quarterly, 2010.

HAKINSON, P.; ROCHESTER, C. The Face and Voice of Volunteering: A Suitable Case for Branding? International Journal of Nonprofit \& Voluntary Sector Marketing, v. 10, n. 2, p. 93-105, 2005.

IBGE - Instituto Brasileiro de Geografia e Estatística. As Fundações Privadas e Associações sem fins lucrativos no Brasil. 20. ed. Rio de Janeiro, 2006. Disponível em: <http://www.ibge. gov.br/home/estatistica/economia/fasfil/fasfil.pdf>. Acesso em: 6 jan. 2013.

MACHADO, A. C. M. Relações interorganizacionais em organizações de Terceiro Setor: reflexões teóricas. Revista Eletrônica de Ciência Administrativa (RECADM), v. 6, n. 1, 2007. Disponível em: <http://revistas.facecla.com.br/index.php/recadm/article/view/245/0>. Acesso em: 7 jan. 2013.

ONU - Organização das Nações Unidas. Handbook on Non-Profit Institutions in the System of National Accounts. New York: United Nations, 2003.

PAUL, M. A. “Born to Be Good?" USA Weekend, July 23-2 5, 1999.

PEROLD, H.; TAPIA, M. N. Servicio Cívico y Voluntariado en Latinoamérica y el Caribe. Service Enquiry/Servicio Cívico y Voluntariado Volumen 2. Buenos Aires: Centro Latinoamericano de Aprendizaje y Servicio Solidario; Johannesburg: Volunteer and Service Enquiry Southern Africa; St. Louis: Washington University, The Center for Social Development; Washington DC: Innovations in Civic Participation, 2007.

SALAMON, L.; ANHEIER, H. In search of Non Profit Sector II: The problem of classification Working Papers of the John Hopkins Comparative Non Profit Sector Project n 3. Baltimore: The John Hopkins Institute for Policies Studies, 1992. Disponível em: <http://www.jhu.edu/ ccss/ pubs/pdf/sector2.pdf $>$. Acesso em: 6 nov. 2013.

SALAMON, L. A emergência do Terceiro Setor - uma revolução associativa global. Revista de Administração, São Paulo, v. 33, n. 1, p. 5-11, jan./mar. 1998.

Partners in public service: Government-nonprofit relations in the modern welfare state. Baltimore, MD: Johns Hopkins University Press, 1995.

SALVATORE, V. A racionalidade do Terceiro Setor. In: VOLTOLINI, R. (Org.). Terceiro setor: planejamento e gestão. 2. ed. São Paulo: Senac, 2004. p. 17-34. 
SILVA, J. O. Novo Voluntariado Social: motivações. In: CONGRESSO BRASILEIRO DE SOCIOlOGIA, 12., 2005, 31 maio a 3 de junho 2005, Belo Horizonte. Anais... Porto Alegre: Sociedade Brasileira de Sociologia, 2005.

SOARES, E. A. R. Entidades beneficentes de assistência social educacionais: uma investigação sobre a medição de desempenho organizacional. 131 f. Dissertação (Mestrado em Ciências Contábeis) - Programa Multiinstitucional e Inter-Regional de Pós-Graduação em Ciências Contábeis - Universidade de Brasília/UFPB/UFPE/UFRN, Recife, 2006. Disponível em: <http:// repositorio.unb.br/handle/10482/2278>. Acesso em: 6 jan. 2013.

SOUZA, L. M.; LAUTERT, L.; HILLESHEIN, E F. Trabalho voluntário, características demográficas, socioeconômicas e autopercepção da saúde de idosos de Porto Alegre. Revista da Escola de Enfermagem da USP, v. 44 n. 3, p. 561-569, 2010. Disponível em: <http://www. scielo.br/scielo.php?pid=S0080-62342010000300003\&script=sci_arttext $>$. Acesso em: 28 dez. 2012.

TOWNSEND, M.; EBDEN, M. I like to think when I'm gone I will have left this a better place. 2008.

VROOM, V. H. Work and motivation. San Francisco, CA: Jossey-Bass, 1964.

Recebido em: 28-12-2015

Aprovado em: 07-11-2016'

Avaliado pelo sistema double blind review.

Editor: Elmo Tambosi Filho

Disponível em http://mjs.metodista.br/index.php/roc 